\title{
Przebiegi chwilowych zmian pola temperatury, struktur oraz stanu naprężeń spawalniczych napawanej rolki linii ciągłego odlewania stali
}

\author{
Instantaneous changes run of thermal field, \\ structures, stress state in the surfacing \\ of the continuous casting line roller
}

\section{Streszczenie}

W artykule przedstawiono wyniki numerycznego modelowania stanu naprężeń spawalniczych w rolce linii ciągłego odlewania stali napawanej warstwami ze stali austenitycznej X5CrNi18-10 oraz martenzytycznej X30Cr13. Przebiegi chwilowych zmian pola temperatury, struktur oraz stanu naprężenia rolki podczas napawania kolejnych ściegów i warstw oraz po zakończeniu napawania zestawiono w prezentacji opracowanej za pomocą modułu animacyjnego przedstawienia wyników, zastosowanego w zmodyfikowanym programie komputerowym RECOVERY 1999.

\section{Wstęp}

Proces napawania, oprócz otrzymania wyrobu o założonym kształcie, powinien zapewnić jego cechy użytkowe przy ograniczeniu niekorzystnego wpływu naprężeń własnych. Sumują się one $z$ naprężeniami eksploatacyjnymi i w przypadku podwyższenia wielkości naprężeń sumarycznych mogą istotnie obniżyć trwałość napawanej części. Zastosowanie numerycznej symulacji stanu naprężenia $w$ warstwie napawanej daje

Dr hab. inż. Eugeniusz Turyk, prof. IS - Instytut Spawalnictwa, Gliwice, prof. dr hab. Igor K. Senczenkow, dr Olga P. Czerwinko - Narodowa Akademia Nauk Ukrainy, Kijów. możliwość analizy tego stanu w warstwach napawanych $w$ zależności od technologii wielowarstwowego napawania, umożliwiając wyjaśnienie przyczyny różnic trwałości elementów napawanych przy użyciu różnych technologii, a eksploatowanych w jednakowych lub zbliżonych warunkach. Problem taki występuje m.in. w przypadku rolek prowadząco-oporowych linii ciągłego odlewania stali (COS), napawanych przy użyciu różnych spawalniczych materiałów dodatkowych. Badania rolek wykazały istotne różnice ilości i głębokości pęknięć eksploatacyjnych w warstwach napawanych drutem zapewniającym warstwę napawaną o składzie chromowej stali martenzytycznej $\mathrm{X} 30 \mathrm{Cr} 13$ oraz drutem zapewniającym warstwę napawaną o składzie chromowo-niklowej stali austenitycznej X5CrNi18-10 [1]. 


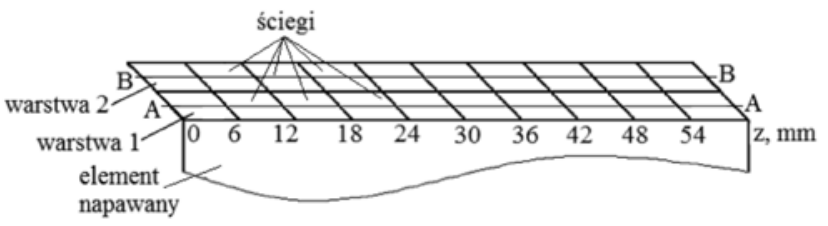

Rys. 1. Schemat napawania - układ ściegów w warstwie 1 i 2 Fig. 1. Surfacing plan - bead sequence in the 1 and 2 layer

Przeprowadzono numeryczną symulację zjawisk cieplno-naprężeniowych stanu naprężenia w napawanych rolkach, w warstwie napawanej z przemianą martenzytyczną i bez tej przemiany.

W celu analizy stanu naprężenia napawanych rolek zastosowano model i metodę obliczeń składu fazowego oraz stanu naprężenia w cylindrycznych częściach napawanych, z wykorzystaniem modelu Bodnera-Partoma i metod teorii narasta-

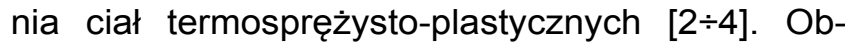
liczenia udziału faz przeprowadzono w oparciu o wykresy CTPc przemian austenitu przechłodzonego podczas chłodzenia ciągłego. Efekt przemian strukturalnych jest uwzględniany przez odkształcenie cieplno-strukturalne. Jest ono funkcją objętości właściwej fazy i udziałów objętościowych faz. Parametry modelu Bodnera-Partoma dla rozpatrywanych stali wyznaczono metodą obliczeniową zgodnie z [5] wg doświadczalnych wykresów rozciągania przy różnej temperaturze [6]. Zadanie dotyczące stanu cieplno-mechanicznego elementów napawanych rozwiązywano za pomocą metody elementów skończonych. Do obliczeń użyto zmodyfikowanego programu komputerowego RECOVERY 1999 [7]. Program ten, po zastosowaniu w nim modułu animacyjnego przedstawienia wyników, zapewnia możliwość śledzenia przebiegu chwilowych zmian pola temperatury, struktur oraz stanu naprężeń spawalniczych napawanej rolki.

\section{Chwilowe zmiany pola temperatury, struktur oraz stanu naprężenia napawanej rolki}

Przeprowadzono symulację procesów zachodzących w rolce o średnicy $126 \mathrm{~mm}$ wykonanej ze stali 34CrMo4 napawanej warstwami o składzie chemicznym odpowiadającym chromowo-niklowej stali austenitycznej X5CrNi18-10 (2 warstwy) i chromowej stali martenzytycznej X30Cr13 (1 warstwa). Rozpatrzono model procesu napawania rolki ze stopniowym narastaniem warstw przy układaniu kolejnych ściegów pierścieniowych (rys. 1).

Temperatura podgrzewania wstępnego wynosi $\mathrm{T}_{0}=300^{\circ} \mathrm{C}$. Badania metalograficzne wykazały, że w strefie wpływu ciepła (SWC) nie zachodzi przemiana martenzytyczna, powodująca powstawanie naprężeń strukturalnych, w związku z tym pominięto wpływ czynnika strukturalnego na poziom naprężeń w rolce.

Czas między układaniem kolejnych ściegów, ich wymiary, temperatura materiału, czas stygnięcia itd. dobierano w taki sposób, aby uzyskać równoważność geometrycznych, energetycznych i pozostałych parametrów procesu technologicznego.

Przebiegi chwilowych zmian pola temperatury, struktur (austenit, bainit, martenzyt) oraz stanu naprężenia (intensywność odkształceń plastycznych $\varepsilon_{i}^{p}$, składowe naprężeń osiowych $\sigma_{z}$ i obwodowych $\sigma_{\varphi}$, intensywność naprężeń $\sigma_{i}$ oraz średnie naprężenie $\sigma_{0}$ ) napawanej rolki zestawiono $\mathrm{w}$ prezentacji opracowanej za pomocą modułu animacyjnego przedstawienia wyników. Przykładowe zbiorcze wyniki obliczeń dla $5 \div 7$ ściegu warstwy napawanej $1 \div 3$ przedstawiono na rysunkach $2 \div 6$.

Po zakończeniu napawania pierwszej warstwy określono, że SWC ma strukturę bainityczną, a struktura rozkładu naprężeń ma charakter „komórkowy”, tj. odpowiadający poszczególnym

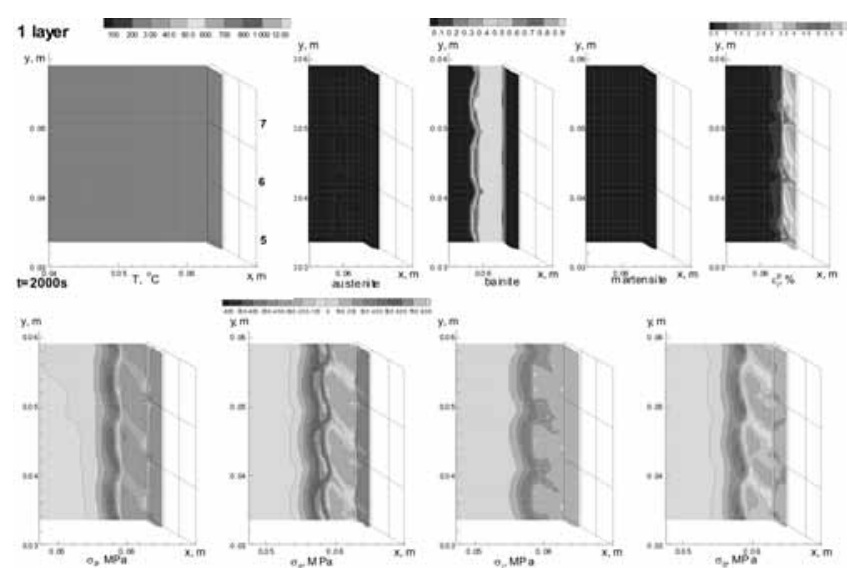

Rys. 2. Pole temperatury, struktur oraz stanu naprężenia rolki po zakończeniu napawania pierwszej warstwy

Fig. 2. Thermal field, structures, and stress state of the roller after first layer surfacing

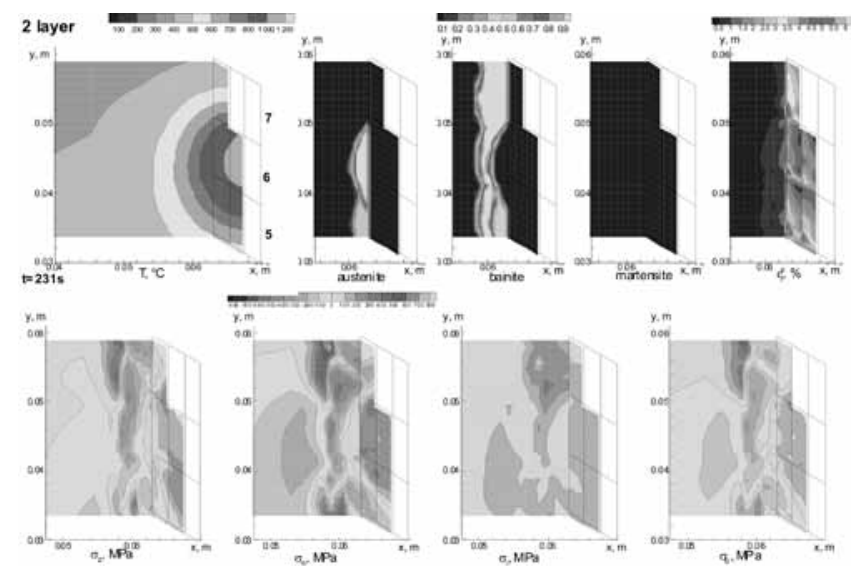

Rys. 3. Pole temperatury, struktur oraz stanu naprężenia rolki w momencie napawania szóstego ściegu drugiej warstwy

Fig. 3. Thermal field, structures, and stress state of the roller in the sixth bead of second layer surfacing 


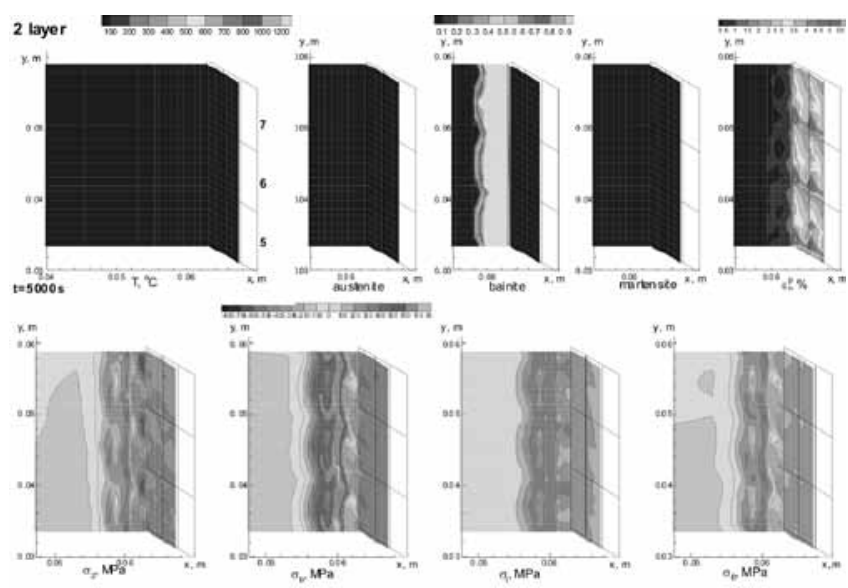

Rys. 4. Pole temperatury, struktur oraz stanu naprężenia rolki po zakończeniu napawania drugiej warstwy

Fig. 4. Thermal field, structures, and stress state of the roller after second layer surfacing

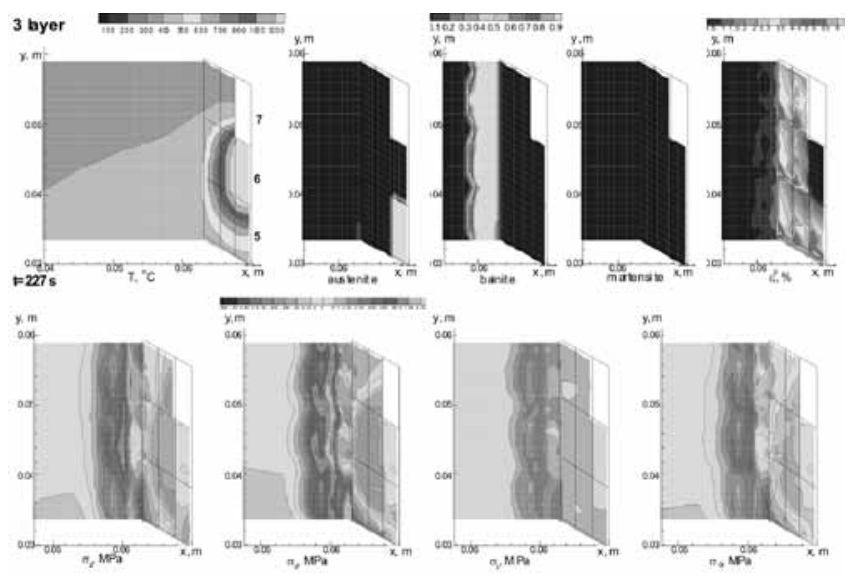

Rys. 5. Pole temperatury, struktur oraz stanu naprężenia rolki w momencie napawania szóstego ściegu trzeciej warstwy

Fig. 5. Thermal field, structures, and stress state of the roller in the sixth bead of third layer surfacing

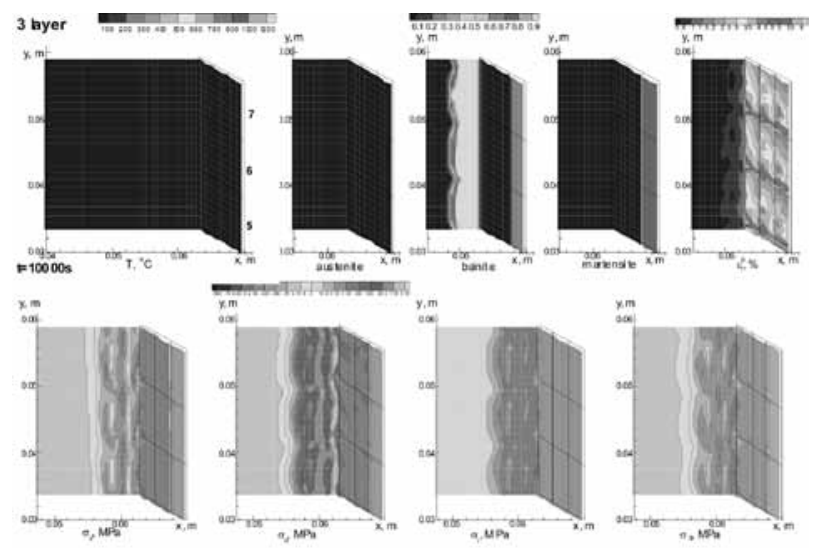

Rys. 6. Pole temperatury, struktur oraz stanu naprężenia rolki po zakończeniu napawania trzeciej warstwy

Fig. 6. Thermal field, structures, and stress state of the roller after third layer surfacing ściegom (rys. 2). Na zestawieniu dotyczącym momentu napawania szóstego ściegu widoczny jest efekt wyżarzenia SWC, w wyniku którego w bainicie utworzyła się strefa o strukturze austenitycznej (rys. 3). Po zakończeniu napawania drugiej warstwy w SWC występują na przemian strefy w stanie ściskanym i rozciaganym (rys. 4). Podczas napawania szóstego ściegu trzeciej warstwy efekt wyżarzenia już nie występuje (rys. 5) i struktura SWC jest bainityczna (rys. 6). Trzecia warstwa napawana ma strukturę martenzytyczną $(80 \%)$ z bainitem $(20 \%)$. W SWC występują wyłącznie naprężenia rozciągające, a w zewnętrznej warstwie napawanej naprężenia ściskające. Wskazuje to na możliwość oddziaływania na stan naprężenia napawanych rolek linii COS przez dobór materiału warstwy napawanej.

Badania mikrostruktury napawanej rolki wykazały zgodność wyników tych badań z rezultatami symulacji struktury SWC, przy tym jednak wynik symulacji struktury trzeciej warstwy napawanej (martenzyt $+20 \%$ bainitu, rys. 6 ) odbiega od wyniku badań metalograficznych tej warstwy, mającej strukturę wyłącznie martenzytyczną. Rozbieżność ta wynika z zastosowania w obliczeniach anizotermicznego wykresu CTPc przemian austenitu przy chłodzeniu ciągłym stali $\mathrm{X} 30 \mathrm{Cr} 13$, a nie wykresu CTPc-S przemian austenitu w warunkach spawalniczych cykli cieplnych, co skutkuje mniejszym udziałem produktów hartowania [8].

W przeprowadzonej analizie przyjęto upraszczające założenie rozpatrzenia tylko spawalniczych naprężeń własnych powstających w napawanych rolkach. Eksploatacji rolek linii COS towarzyszą także:

- eksploatacyjne naprężenia cieplne przy cyklicznej zmianie temperatury rolki;

- naprężenia wywołane obciążeniami mechanicznymi, przede wszystkim naciskiem wlewka ciągłego (zmęczenie mechaniczne wskutek zginania obracającej się rolki);

- zużycie ścierne w warunkach tarcia metal-metal przy podwyższonej temperaturze oraz zużywanie zmęczeniowe przez łuszczenie;

- zużycie korozyjne powierzchni i pękanie korozyjne, któremu sprzyja obecność naprężeń rozciągających i obciążenia zmienne oraz podwyższona temperatura; proces zużycia korozyjnego może być uwzględniony w ocenie trwałości napawanych rolek np. na podstawie zależności między naprężeniem a czasem pękania korozyjnego [9];

- zmiany strukturalne w warstwach napawanych i SWC. Cykl cieplny eksploatacji rolek nie powoduje zmiany struktury warstw napawanych austenitycznej i martenzytycznej, natomiast może mieć wpływ na proces wydzieleniowy w napoinach, jak i na odpuszczanie w SWC.

Uwzględnienie wpływu tych procesów na stan naprężenia stanowi kierunek dalszych prac dotyczących trwałości eksploatacyjnej napawanych rolek linii COS. 


\section{Wnioski}

Moduł animacyjnego przedstawienia wyników, zastosowany $w$ programie komputerowym RECOVERY 1999, zapewnia możliwość śledzenia przebiegu chwilowych zmian pola temperatury, struktur oraz stanu naprężeń spawalniczych napawanej rolki.

Wyniki przeprowadzonej analizy stanu naprężenia rolek napawanych drutem zapewniającym warstwę napawaną o składzie chromowo-niklowej austenitycznej stali $\mathrm{X} 5 \mathrm{CrNi18-10}$ oraz drutem zapewniającym warstwę napawaną o składzie chromowej stali martenzytycznej X30Cr13 pozwalają na wyjaśnienie różnic trwałości eksploatacyjnej tych rolek. W napawanej warstwie austenitycznej naprężenia własne są rozciągające, natomiast w warstwie martenzytycznej ściskające. Ściskające naprężenia zwiększają wytrzymałość zmęczeniową powierzchniowej warstwy roboczej.

\section{Literatura}

[1] Turyk E., Tejszerska D., Czwórnóg B., Sędek P., Dusza R., Zeman M.: Numeryczna i doświadczalna analiza stanu naprężeniowo-odkształceniowego części maszyn z warstwą roboczą napawaną wielowarstwowo, zapewniającą zwiększenie żywotności elementów maszyn hutniczych pracujących w warunkach zmiennych cykli cieplno-naprężeniowych. Sprawozdanie $\mathrm{nr} \mathrm{Ha}-51$ z projektu badawczego KBN nr 3 T08C 046 26. Gliwice 2006.

[2] Bodner S.R., Partom Y.: Constitutive equations for elasticviscoplastic strain hardening materials. Journal of Applied Mechanics 1975, no. 6/1975.

[3] Bodner S.R.: Plasticity over a wide range of strain rates and temperatures. Archives of Mechanics vol. 57, issue 2-3/2005.

[4] Сенченков И.К., Рябцев И.А., Турык Э.: Использование методов наращивания термовязкопластических тел для моделирования процесса наплавки. Second International Conference „Mathematical modelling and information technologies in welding and related processes", Katsiveli 2004.
[5] Senczenkow I., Turyk E.: Określenie parametrów modelu Bodnera-Partoma termolepko-plastycznego odkształcania materiałów dla stali 34CrMo4, X30Cr13 i X5CrNi18-10. „Biuletyn Instytutu Spawalnictwa" nr 2/2007.

[6] Безухов Н.И, Бажанов В.Л., Гольденблат И.И., Николаенко Н.А., Синюков А.М.: Расчеты на прочность, устойчивость и колебания в условиях высоких температур. Изд. Машиностроение, Москва 1965.

[7] Хромов В.Н., Сенченков И.К.: Упрочнение и восстановление деталей машин термоупругопластическим деформированием. Изд. ОГСХА, Орел 1999.

[8] Brózda J., Pilarczyk J., Zeman M.: Spawalnicze wykresy przemian austenitu CTPC-S. Wyd. Śląsk, Katowice 1983.

[9] Adamiec P., Dziubiński J.: Wytwarzanie i właściwości warstw wierzchnich elementów maszyn transportowych. Wydawnictwo Politechniki Śląskiej, Gliwice 2005.

\section{4 METAL.PL}

\section{Ponad 2000 podwykonawców z całego świata}

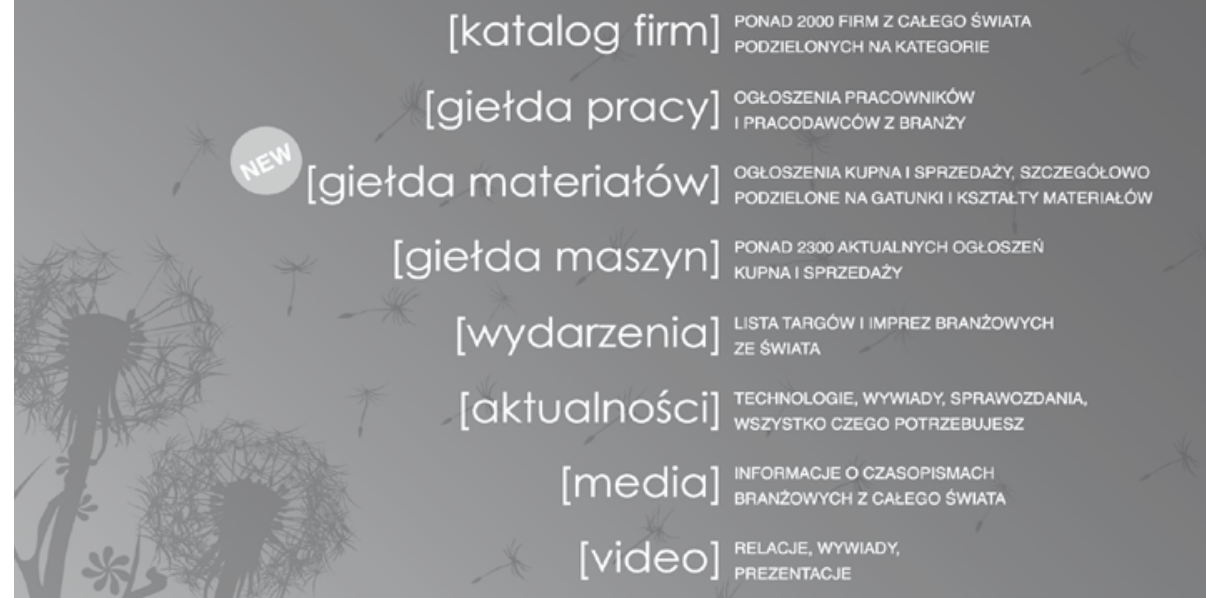

[katalog firm] PONAD 2000 FRM Z Z CALEGO SWIATA

[giełda pracy] IPRAaCODANCOACOWZ BRANZY
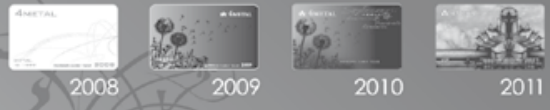

GET THE MEMBERSHIP 